\title{
An evaluation of randomized controlled trials on nutraceuticals containing traditional Chinese medicines for diabetes management: a systematic review
}

\author{
Junnan Shi ${ }^{1}$, Hao Hu${ }^{1}$, Joanna Harnett ${ }^{2}$, Xiaoting Zheng ${ }^{1}$, Zuanji Liang ${ }^{1}$, Yi-Tao Wang ${ }^{1 *}$
} and Carolina Oi Lam Ung ${ }^{1,2^{*}}$ (i)

\begin{abstract}
Background: Nutraceuticals containing traditional Chinese medicine (TCM) are promoted for use in the management of diabetes. The evidence to support such use is largely unknown. This study aimed to summarise and evaluate the literature reporting the results of randomized controlled trials (RCTs) investigating the effects of nutraceuticals in people living with diabetes.
\end{abstract}

Methods: Literature from four electronic databases (PubMed, Scopus, CINAHL and Web of Science) was searched following PRISMA guidelines to yield RCT publications on nutraceutical for diabetes management published since 2009. The quality of reporting was assessed using the CONSORT 2010 checklist statement. Risk-of-bias for each study was assessed using the Cochrane risk of bias tool.

Results: Out of 1978 records identified in the initial search, 24 randomized, double/triple-blinded, controlled trials that investigated the effect of nutraceuticals covering 17 different TCM herbs for diabetes management were selected. Participants included people who were diabetic $(n=16)$, pre-diabetic $(n=3)$ or predisposed to diabetes $(n=5)$. Sample sizes ranged between 23 and 117 for 2 arms, or 99-165 for 3 arms. Comparisons were made against placebo $(n=22)$, conventional medicine $(n=1)$, or regular diet $(n=1)$ for a duration between 4 and 24 weeks. All but one study tested the effect on fasting blood glucose levels $(n=23)$ or glycated haemoglobin levels $(n=18)$, and/ or postprandial 2-h blood glucose levels $(n=4)$ as the primary outcomes. Nineteen studies reported some statistically significant reductions in the respective measures while 5 studies showed no effect on primary or secondary outcomes. None of the included studies met all the criteria for the CONSORT guidelines. Incomplete reporting about randomization and blinding, and a lack of ancillary analyses to explore other influential factors and potential harms associated with the use were repeatedly noted. Based on the Cochrane risk-of-bias tool, 19 studies were deemed to have a high risk of bias mainly attributed to sponsor bias.

Conclusions: There is some evidence to suggest positive clinical outcomes in response to the administration of a range of nutraceuticals containing TCM in the management of diabetes. However, these results must be interpreted with caution due to the overall low quality of the trials.

Keywords: Nutraceuticals, Supplements, Traditional Chinese medicine, TCM, Blood glucose, Diabetes, Randomized clinical trial, RCT

\footnotetext{
*Correspondence: ytwang@um.edu.mo; carolinaung@um.edu.mo

†unnan Shi and Hao Hu share co-first authorship

1 State Key Laboratory of Quality Research in Chinese Medicine, Institute

of Chinese Medical Sciences, University of Macau, Taipa, Macao

Full list of author information is available at the end of the article
} 


\section{Background}

The prevalence of diabetes has been increasing worldwide. With population growth, aging and urbanisation, and related lifestyle changes, it is estimated that diabetes affects 439 million adults aged from 20 to 79 years, accounting for $7.7 \%$ of the global population, especially in developing countries [1]. At the same time, diabetes itself is a multi-morbid metabolic disorder, and in the longterm it can cause damage and dysfunction of different organs, leading to decreased quality of life and increased mortality [2]. These factors would have a significant economic impact on global health care. Based on the current pathological and physiological understanding of diabetes, receiving insulin therapy and oral hypoglycaemic agents are the most common medical treatment for the disease $[3,4]$.

Traditional Chinese medicine (TCM) is an important form of complementary medicine. Numerous studies have reported that some traditional herbs and plants have a significant effect on many aspects of managing diabetes, such as Momordica charantia L. (Cucurbitaceae), Trigonella foenum graecum L. (Leguminosae) and also some active components like plant polyphenols [3-6]. As anti-diabetic medicinal plants tend to be more affordable and reportedly have less serious side-effects than synthetic drugs, people are increasingly willing to choose TCM as a complementary form of diabetes self-management $[7,8]$. According to China Customs statistics, the total value of TCM import and export reached 4.6 billion USD in 2016, accounting for $4.45 \%$ of the total value of the import and export of Chinese pharmaceutical products [9]. However, high policy thresholds and trade barriers in many developed countries have hindered the process of internationalization of TCM. For instance, in the countries of European Union, herbal medicines for human use must follow the latest legislations and different requirements before they are authorized. Another marketing pathway is for eligible herbal medicines to be marketed as dietary supplements which are subject to the food regulations [10-12].

Nutraceuticals and dietary supplements are widely used, and a survey from the Centers for Disease Control and Prevention in United States showed that 20\% of adults used supplements that contained at least one plant ingredient [13]. The terms "nutraceuticals", "dietary supplements" and "functional foods" are often been used interchangeably. According to the definitions given by the Canadian health department and that of the United States and China [14-16], adding the purpose of this review, "nutraceuticals" are defined as "products composed of one or more substances, which have physiological benefit or provide protection against chronic diseases, are isolated from foods, generally sold in medicinal forms (such as pills, powder potions), and not usually associated with food, especially not including fortified foods". Although nutraceuticals containing TCM are promoted for their positive effects in the management of diabetes, such as reducing the blood glucose levels, their efficacy is largely unknown [17]. However, some nutraceutical formulations containing specific TCM have been clinically tested to verify their effectiveness in the management of diabetes including the effects of ginger supplements on insulin resistance and cinnamon supplements for glycaemic control in patients with type 2 diabetes mellitus (T2DM) $[18,19]$. To date, the literature reporting randomized controlled trials (RCTs) involving nutraceuticals containing TCM has not been systematically reviewed. Therefore, the aim of this review is to summarise and evaluate the quality of studies reporting the results of randomised controlled trials investigating the effects of nutraceuticals containing TCM in the management of diabetes.

\section{Methods}

The systematic review conforms to the Preferred Reporting Items for Systematic Reviews and Meta analyses (the PRISMA statement) and utilizes the Consolidated Standards of Reporting Trials Statement (the CONSORT statement), and the Cochrane Collaboration's Risk of Bias tool for evaluating the quality of the studies included the review.

\section{Eligibility criteria \\ Types of studies}

Randomized, double or triple-blinded, controlled trials evaluating the effects of nutraceuticals containing TCM in diabetes and published in English were included. Nutraceuticals that contained TCM listed in the Chinese Pharmacopoeia were eligible for inclusion in this review [20].

\section{Participant characteristics}

Studies that included patients regardless of the gender, age, or race/ethnicity were eligible. The target populations included people living with diabetes, pre-diabetes or people predisposed to diabetes. Diabetes was diagnosed clinically according to the American Diabetes Association (ADA) diagnostic criteria, including Type 1 diabetes mellitus (T1DM), Type 2 diabetes mellitus (T2DM) and other specific types of diabetes [21]. ADA reintroduced pre-diabetes to cover impaired glucose tolerance (IGT) and impaired fasting glucose (IFG) in 2005 , however, any definition of pre-diabetes limited to IGT and/or IFG does not include other risk factors for diabetes [22, 23]. People who are predisposed to diabetes are affected by many increased risks, such as obesity, 
hypercholesteremia, metabolic syndrome (MetS), which have been evidenced from several studies to increase the risk of diabetes $[24,25]$.

\section{Types of interventions}

Patients in the control group were treated with placebo or/and conventional medicines or in addition to their regular diet. Patients in the treatment group were given nutraceuticals containing TCM in addition to the conventional medicines. Details of both the placebo and nutraceutical were required, including the TCM ingredients, formulation composition, extraction technology and any declarations of financial support.

\section{Outcome measures}

Studies including three widely accepted diagnostic criteria for diabetes were eligible: fasting blood glucose levels (FBG), postprandial 2-h blood glucose levels (PBG), and glycated haemoglobin (HbA1c) [26-29]. Studies reporting other outcomes such as fasting insulin, postprandial insulin, insulin sensitivity, the level of Homeostatic Model Assessment for Insulin Resistance index (HOMA-IR), the quantitative insulin sensitivity check index (QUICKI), and $\beta$-cell function were also eligible for inclusion [30, 31].

\section{Quality assessment methods}

The quality of the studies included was assessed using the 24-item version of the Consolidated Standards of Reporting Trials statement (CONSORT) [32]. The 2010 checklist provides a set of guidelines that may be used to identify the strengths and weaknesses of clinical trials for both pharmacological and nonpharmacological treatments. Two authors (JS, COLU) independently assessed the risk of bias for each article included, based on the 12 criteria recommended by the Cochrane Review Group [33]. Disagreements were settled through discussion or consultation with the corresponding authors.

\section{Search methods}

Four electronic databases, including PubMed, Scopus, CINAHL and Web of Science were searched for RCT studies evaluating nutraceuticals containing TCM for diabetes management for the period 2009 until February 1, 2019. Search terms included: (nutraceutical* OR supplement*) AND (diabetes OR glucose OR insulin*) AND (clinical OR trial*). The PubMed database has the special medical terminology "MeSH", so the terms "Glucose Metabolism Disorders [Mesh]" and "Dietary Supplements[MeSH]" were added to the search in this database to ensure that results were not missed.

\section{Exclusion criteria and screening}

Abstracts and full text articles were rigorously reviewed for meeting the inclusion criteria. Non-TCM-related RCTs were screened for inclusion in three stages during the title retrieval: (1) review, meta-analysis, protocol were not included; (2) vitamin, mineral, fortified food and beverage, probiotic and prebiotic were also not included; (3) herbal ingredients not listed in the Chinese Pharmacopoeia were not included. In addition, observational studies that were limited by heterogeneity or reliance on self-reported nutritional data were not included.

\section{Data collection and analysis Selection of studies}

Two review authors (JS, COLU) independently screened the titles and abstracts identified in the search for meeting the inclusion criteria outlined above. Full texts of potentially relevant articles were retrieved for detailed assessment. The CONSORT and Cochrane evaluations were independently implemented by two authors (JS, COLU) in accordance with the guidelines, and discrepancies were discussed and resolved by agreement or consultation with 2 others author (HH, YTW).

\section{Data extraction and management}

Data were extracted based on study characteristics that included patients, methods, interventions and outcomes, into a standardised data extraction form. Reasons for the exclusion of studies were recorded. For eligible studies, two review authors (JS, COLU) extracted data, evaluated information independently and any disagreements were resolved by discussion, or by involving a third author.

\section{Data synthesis and analysis}

References were categorsied and filed using Endnote X9 and data extracted and categorized using Excel 2013. Data was extracted for primary outcomes (FBG, PBG, and HbA1c levels) and secondary outcomes (fasting insulin, postprandial insulin, insulin sensitivity, HOMAIR, QUICKI, and $\beta$-cell function). Treatment effect was estimated with mean difference in the final value of FBG or PBG between the intervention and the placebo groups. The inverse variance-weighted method was used for the pooling of mean difference and the estimation of $95 \%$ confidence interval; the significant level was set at $P<0.05$ [34].

All included studies were assessed for compliance with the 2010 guidelines of the CONSORT statement. To measure compliance, a grading system was devised for each criterion, where the reviewer gave a score of " 0 " if the item was not present at all, a " 1 " if the feature was partially present, such as some aspects of the CONSORT item were missing or unclear, and a " 2 " if the item was 
present and clear. By applying the CONSORT criteria to all relevant sections of each study, an overall summary of the study's quality as a clinical trial was produced. The evaluation method was checked for validity and consistency by 3 co-authors [35].

The assessment using the Cochrane risk-of-bias tool also has its own judging criteria. The results of each items were divided into three categories: "Low risk of bias", "Unclear risk of bias" and "High risk of bias". All criteria are suggested in the Cochrane guidelines. At the same time, this was also be checked by 3 co-authors [36].

\section{Results}

\section{Study selection}

We identified 892 potentially relevant articles from 1978 initial records after duplicates were removed. An additional 845 records were excluded during screening or a range of reasons: review or meta-analysis or protocol articles $(n=146)$; vitamin $(n=170)$; mineral $(n=52)$; fortified food and beverage $(n=29)$; probiotic and prebiotic $(\mathrm{n}=50)$; or not TCM $(\mathrm{n}=398)$; crossover trials $(\mathrm{n}=2)$, observational clinical trials $(\mathrm{n}=1)$ or single-blinded trials $(\mathrm{n}=5)$; did not include biomarkers of diabetes $(\mathrm{n}=6)$ and 1 article had a lack of access to full text. No additional eligible studies were found after manually searching the four electronic databases. Ultimately, 24 eligible studies, involving numbers of the participants between 23 and 165 , and study durations from 4 to 24 weeks, were identified. The screening process is summarized in a flow diagram that followed the Prisma guidelines (Fig. 1).

\section{Study characteristics}

The 24 studies were all published between 2009 and February 1, 2019 (see Table 1). All 1742 participants were from 11 different areas and countries. Among them, 644 were male and 900 were female (two trials did not report the number of patients according to gender). The study sample size ranged between 23 and 117 for 2 arms, or 99 to 165 for 3 arms. Seven RCTs had a small sample size of less than 50, 11 RCTs had a sample size between 50 and 100 , and the other 6 RCTs ranged in sample size between 100 and 200.

Seventeen herbal ingredients used in Chinese herbal formulations were involved: cinnamon $(\mathrm{n}=4)$, ginger $(\mathrm{n}=2)$, curcuminoids $(\mathrm{n}=2)$, Silybum marianum $(\mathrm{n}=2)$, propolis $(\mathrm{n}=2)$, Andrographis paniculata $(\mathrm{n}=1)$, garlic $(\mathrm{n}=1)$, ginseng $(\mathrm{n}=1)$, Ginkgo biloba $(\mathrm{n}=1)$, Glycyrrhiza glabra $\mathrm{L} .(\mathrm{n}=1)$, Morus alba $(\mathrm{n}=1)$, Nigella sative $(\mathrm{n}=1)$, flaxseed $(\mathrm{n}=1)$, daidzein $(\mathrm{n}=1)$, Aloe vera $(\mathrm{n}=1)$, psyllium $(\mathrm{n}=1)$, Cornus mas $(\mathrm{n}=1)$.

The study populations included diabetes patients $(n=16)$, pre-diabetes $(n=3)$ or people with predisposing factors of diabetes $(n=5)$. Predisposing factors included overweight or obese populations, and those with hypercholesterolemia and metabolic syndrome. What's more, comparisons were made against placebo $(n=22)$, conventional medicine $(n=1)$ and regular diet $(n=1)$.

Of the 24 studies, 23 tested the effect on FBG levels $(\mathrm{n}=23)$, PBG levels $(\mathrm{n}=4)$ and HbA1c levels $(\mathrm{n}=18)$ as the primary outcomes. Nineteen studies reported some statistically significant reductions in the respective measures while 5 studies showed no effect on primary or secondary outcomes.

\section{CONSORT evaluation}

Table 2 presents a summary of CONSORT quality assessment of the 24 studies included in the review. No studies met all the CONSORT criteria. Reasons for this were a lack of explanation about how the sample size was determined, how randomisation was performed, and what interventions were in place to ensure blinding; a lack of ancillary analyses to explore other influential factors; and a lack of reporting about possible harms associated with the use of the nutraceuticals.

All 24 studies reported randomisation, but only 15 studies reported specific methods for random sequence generation, 10 studies referred to a randomisation number table with 5 of them reporting randomisation procedures; and 2 used block randomisation to determine the procedures; the remaining 3 studies used computer Random Allocation Software. Only 3 studies fully described the implementation process, including how randomisation sequences were generated, who recruited the subjects, and who intervened to implement them. Only 1 study completely reported the specific blinding procedures, and 17 referred to blinding but lacked specific procedures, such as what interventions were in place to ensure blinding. The remaining 6 studies did not mention blinding procedures. Only 7 studies reported the primary and secondary outcomes of each subgroup, including both the estimated value and precision, while the remaining 17 were incomplete statements; 2 studies presented the ancillary analyses to explore other influential factors, including subgroup analysis and calibration analysis, 3 statements were incomplete and 19 were not presented at all. Seven studies reported unintended consequences or possible harms in each subgroup, 3 of which were gastrointestinal adverse events, and the remaining 17 did not report adverse events or possible harms.

\section{Risk of bias}

None of the 24 studies met the Cochrane criteria for low risk of bias. Six studies had an unclear risk of bias overall, and the remaining 18 had a high risk of bias. Table 3 presents a summary of the Cochrane evaluation of the 


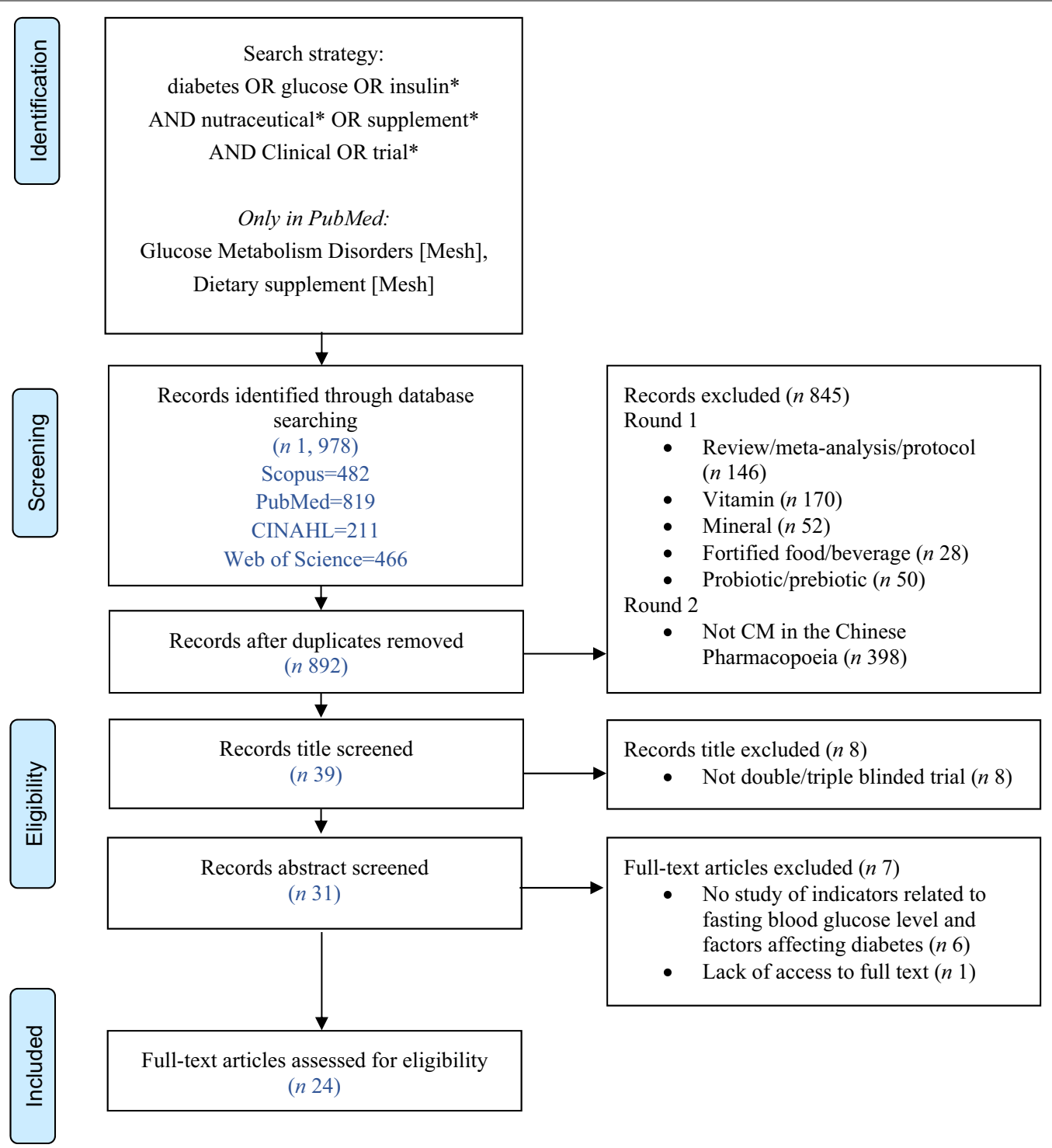

Fig. 1 Prisma 2009 flow-chart summary of systematic review search process

24 studies. Overall, there was a lack of detail reported to adequately assess their potential risk of bias. Only a few studies specifically reported the allocation details of how to generate and conceal the sequence during the randomization allocation.

Meanwhile, many studies lack a report on how blinding of participants, personnel, and outcome assessors was performed. Because of this, eight studies have unclear performance bias and two have high performance bias. Similarly, ten studies have unclear detection bias and another three have high detection bias after evaluating the blinding of outcome assessors. To ensure the data integrity, five studies showed the unclear attrition bias, and one showed high bias, the most important of which was the lack of P-values compared to baseline data and lack of the difference between pre- and post-intervention changes. The bias of the selective reporting in 12 studies were unknown, and another study had a high reporting bias. Seven studies have academic high risk of bias. Only six studies had low sponsor bias and the rest had high and unclear risk of bias.

\section{Discussion}

This systematic evaluation of the literature identified evidence to support the use of nutraceuticals containing TCM to improve FBG, PBG, and HbA1c levels. However, shortcomings in the quality of the study design and reporting and potential bias were identified. While 


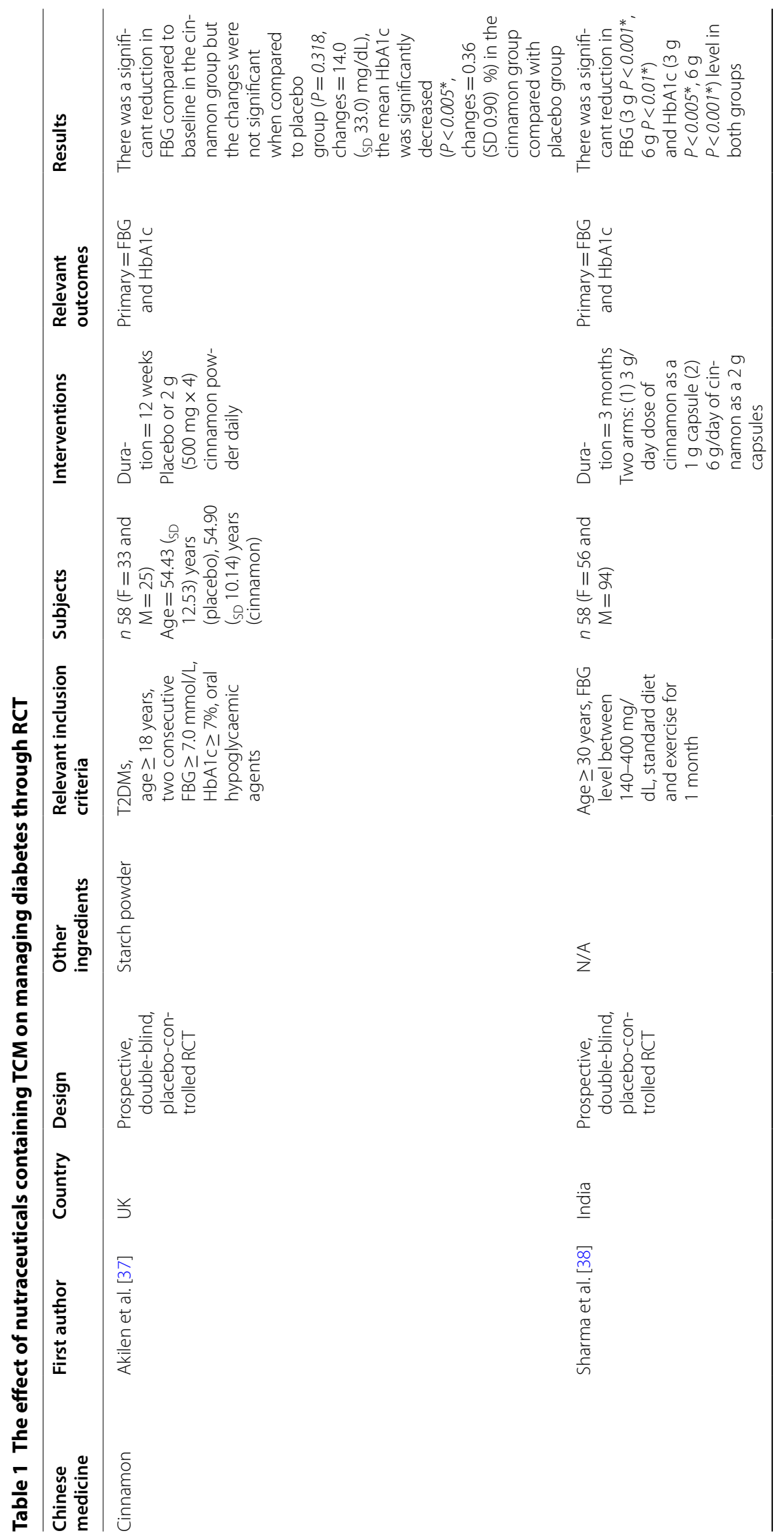




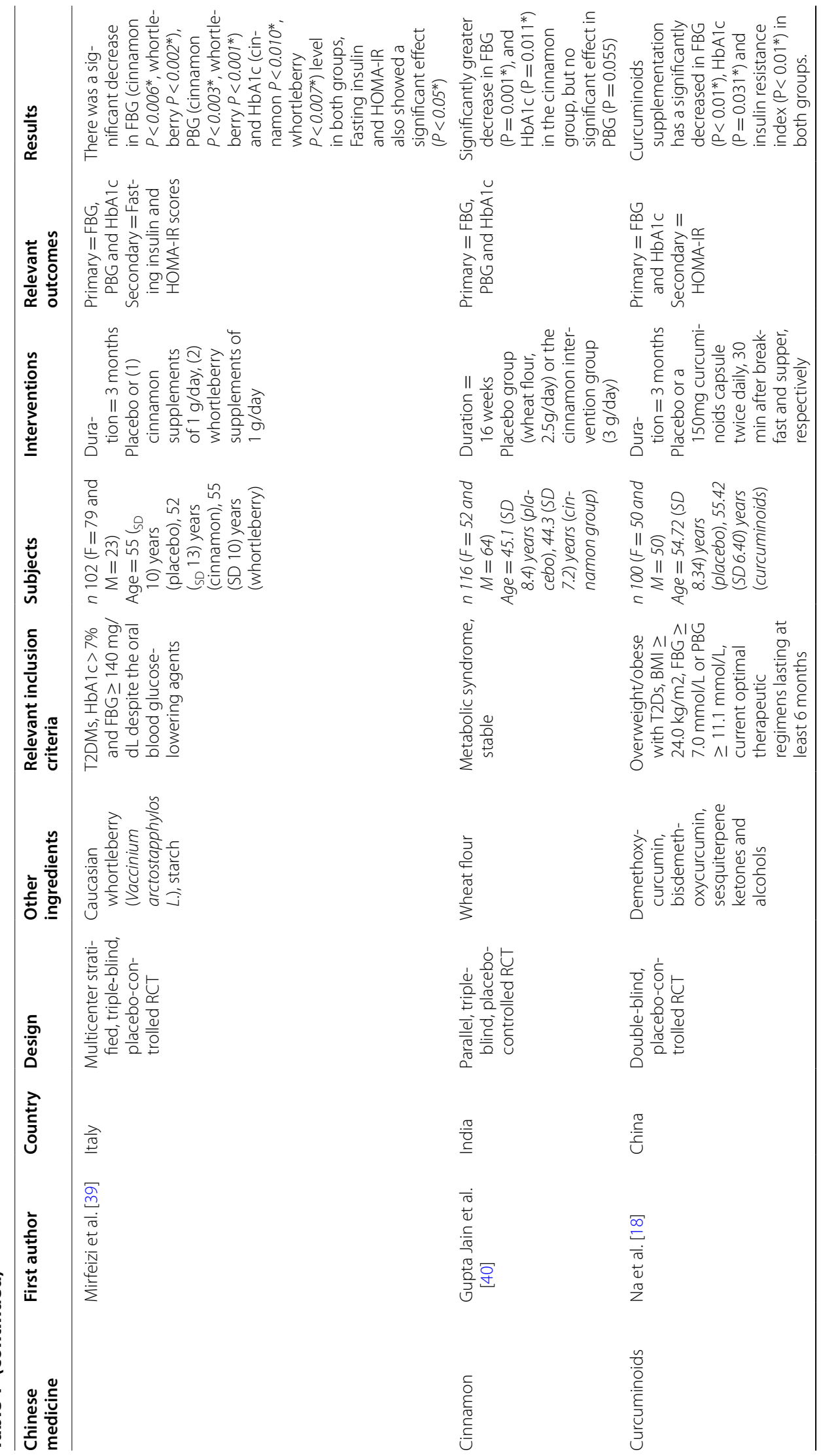




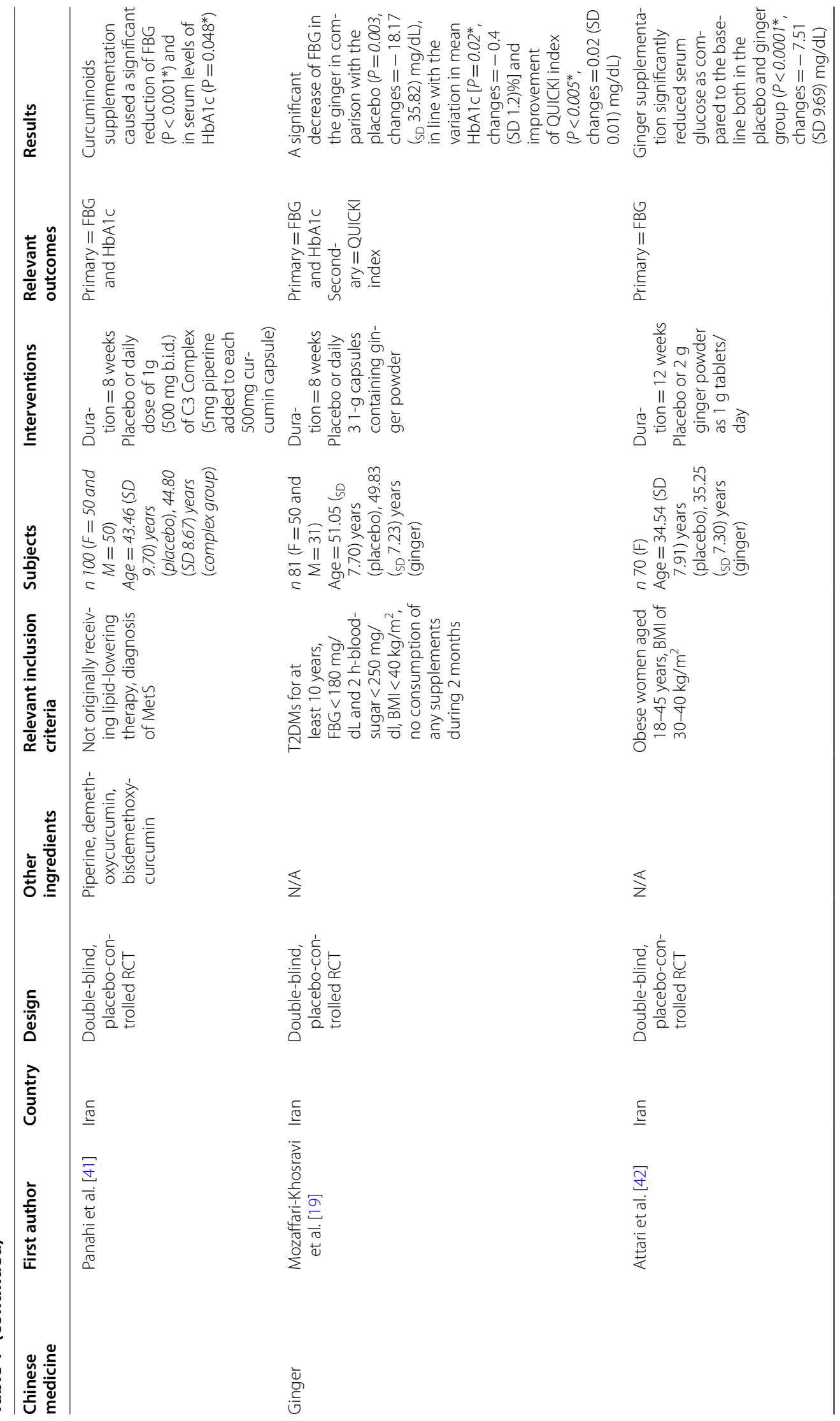




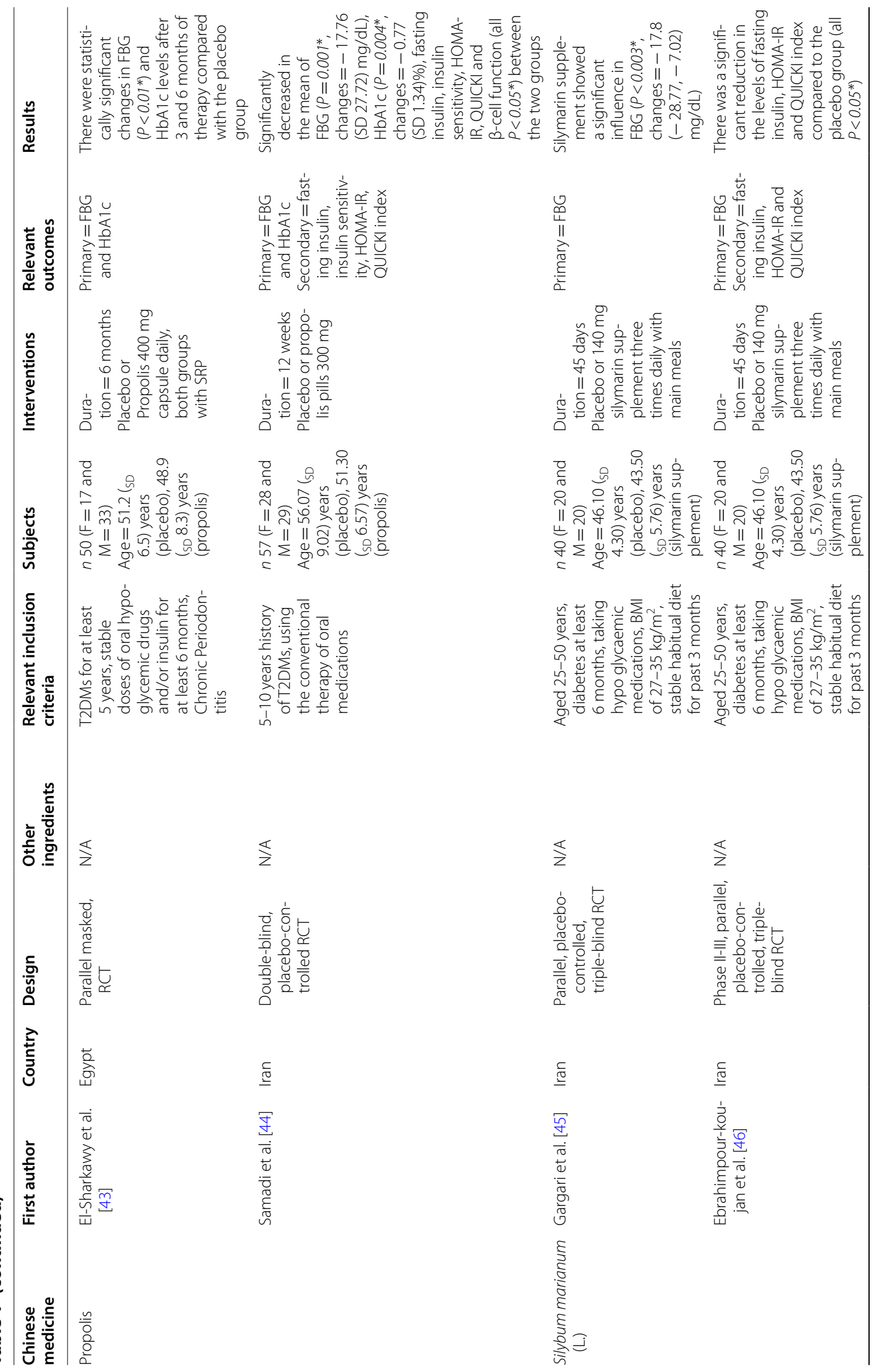




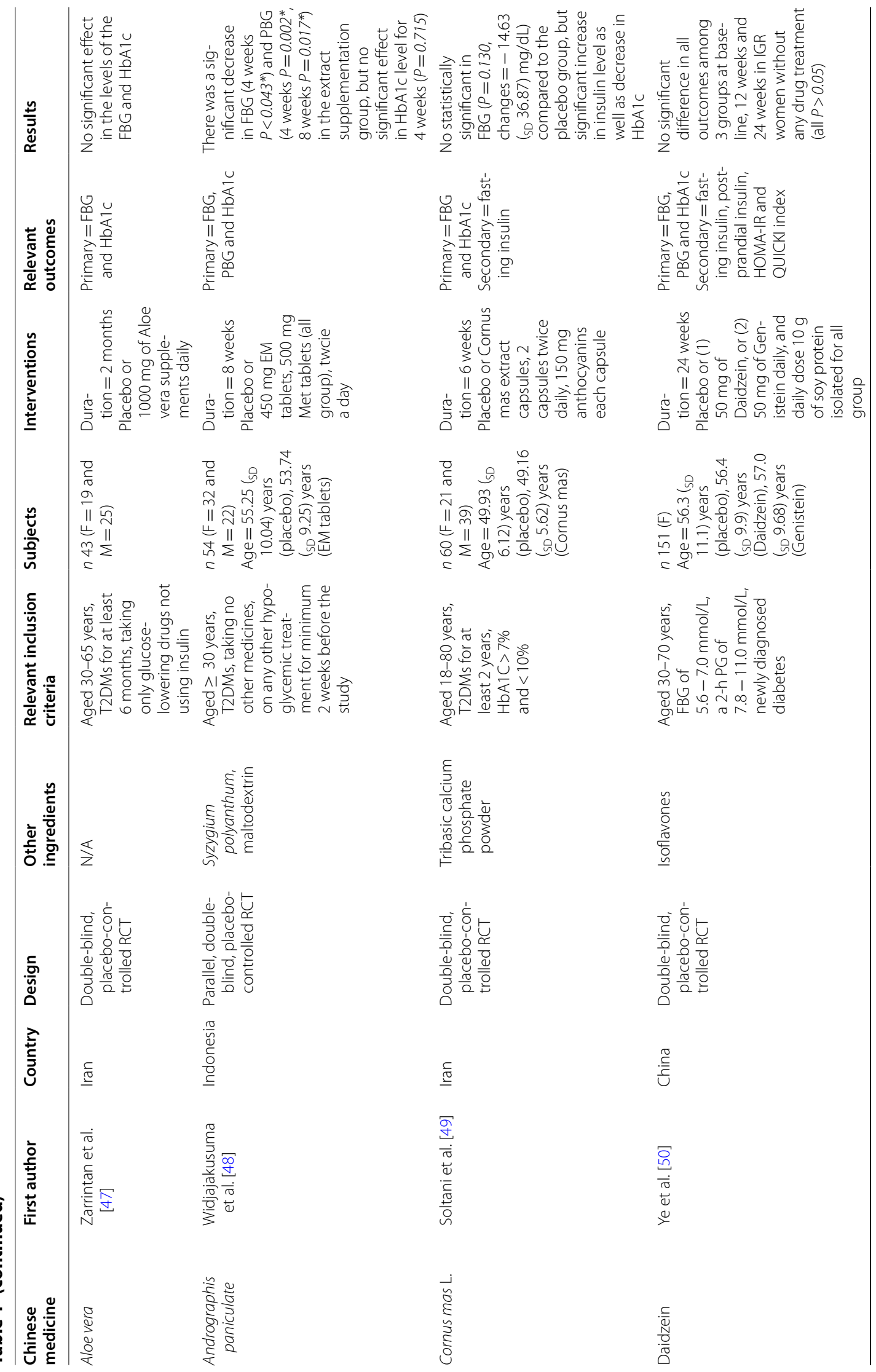




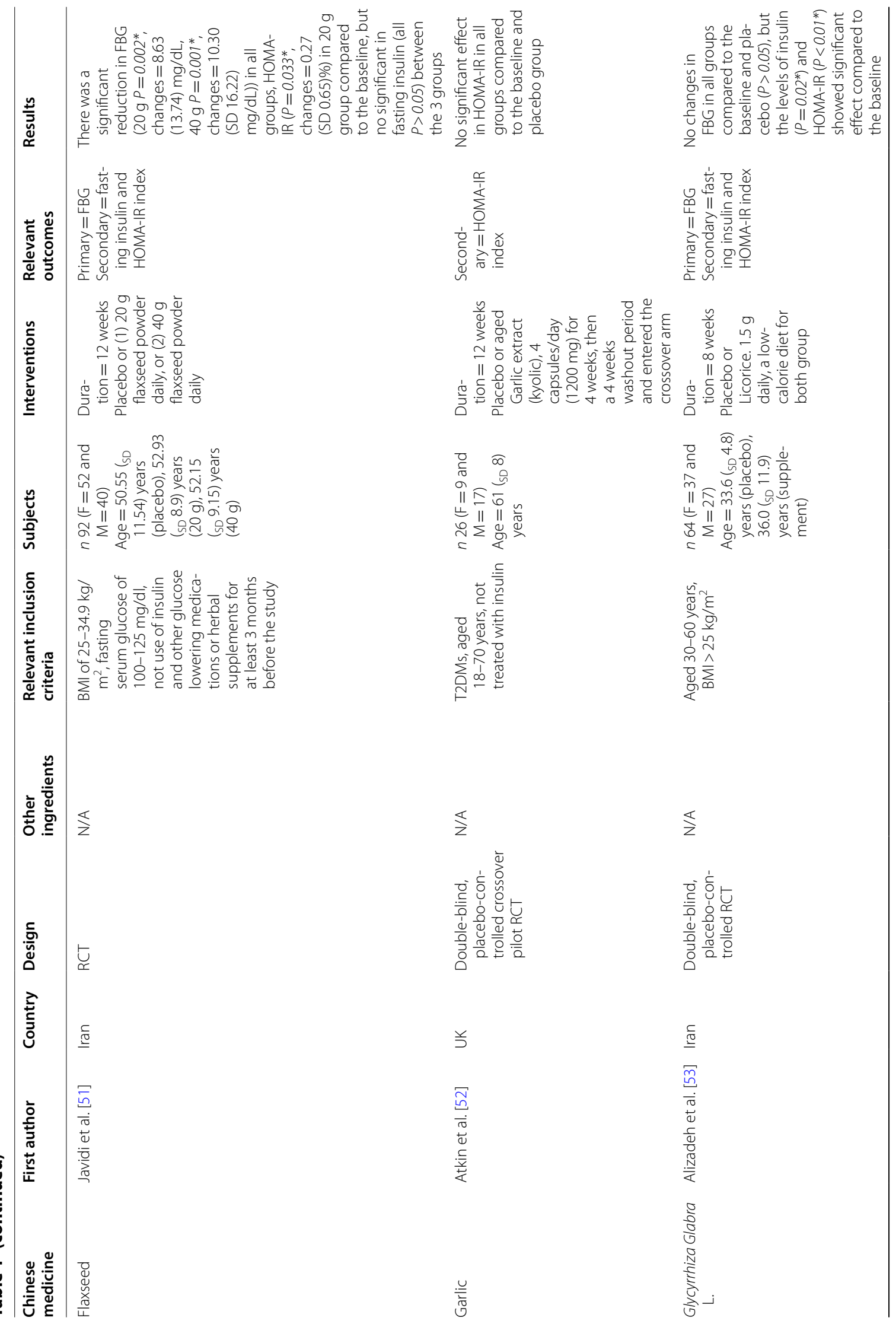




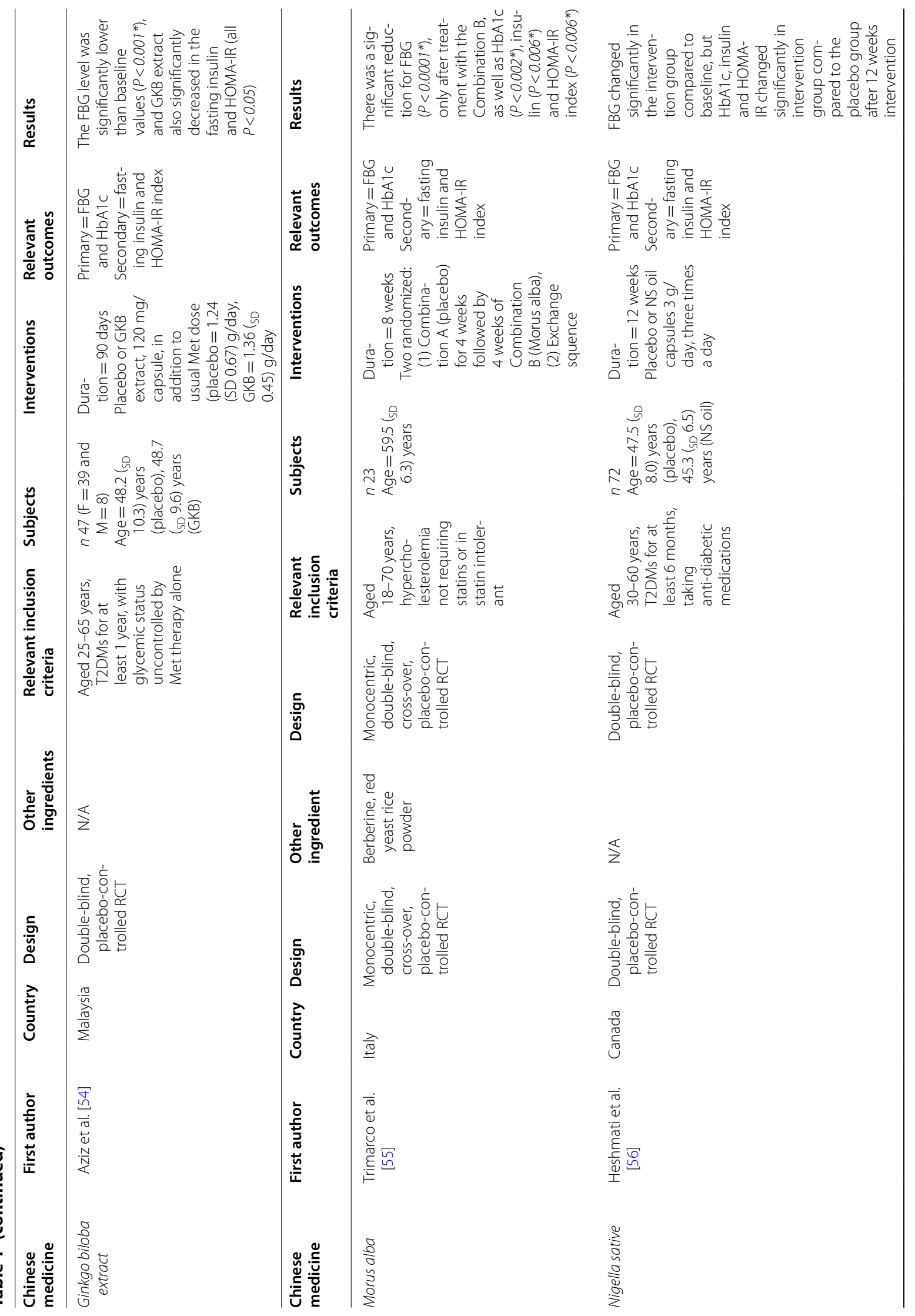




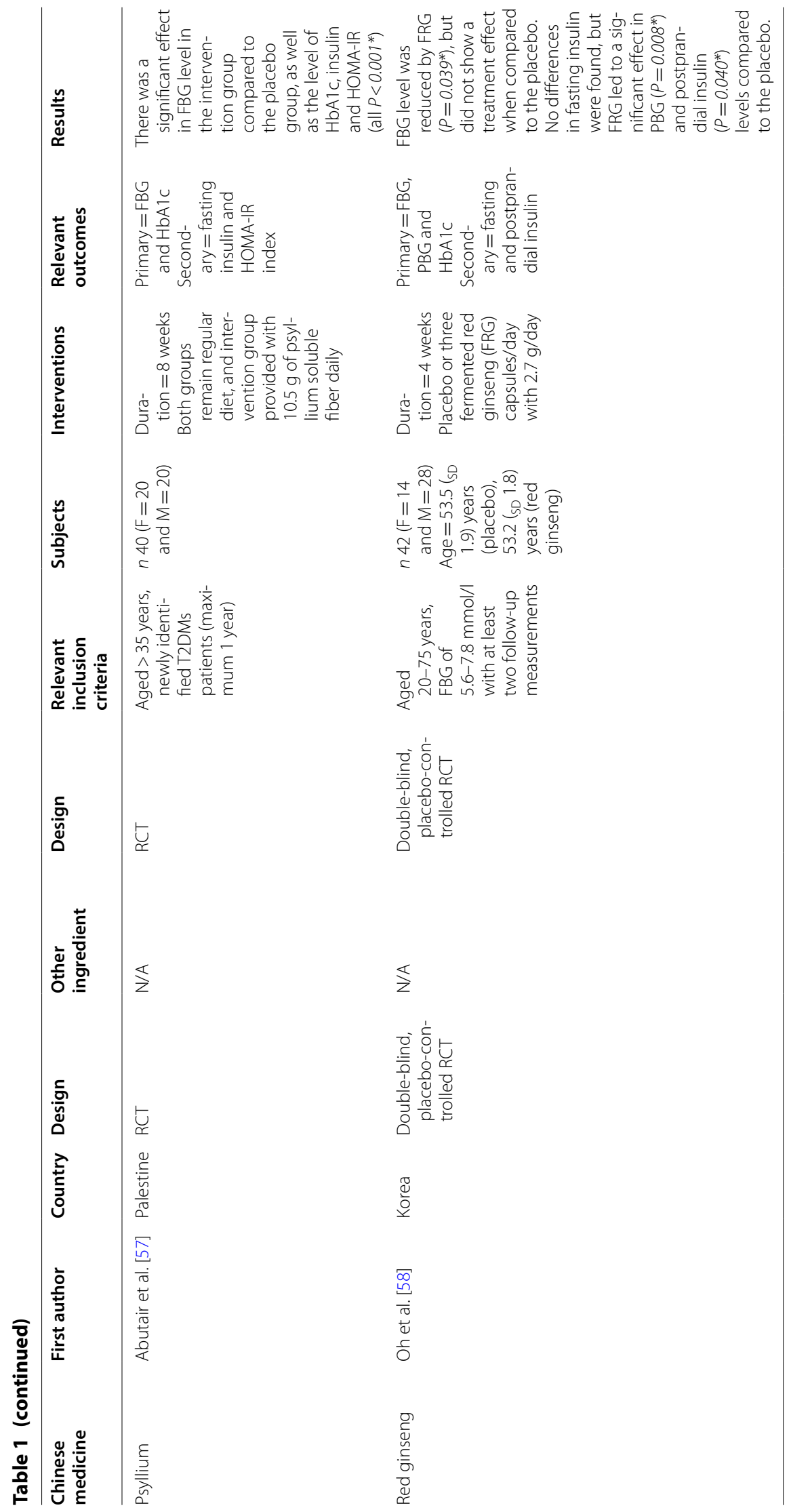


Table 2 Evaluation of included treatment studies using the CONSORT checklist

\begin{tabular}{|c|c|c|c|c|c|c|c|c|c|c|c|c|c|c|c|c|c|c|c|c|c|c|c|c|}
\hline & & 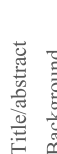 & 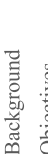 & 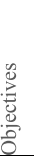 & & & & & & & & & 悬 & 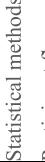 & & $\Rightarrow$ & & & & 息 & & 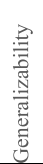 & & : \\
\hline \multirow[t]{4}{*}{ Cinnamon } & Akilen et al. [37] & 0 & - & $\bullet$ & 8 & 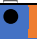 & • & $\bullet$ & $\bullet$ & $\mathbf{0}$ & 0 & 0 & 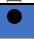 & - & - & $\bullet$ & & - & 0 & 0 & $\bullet$ & 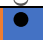 & $=$ & $\circ$ \\
\hline & Shar & - 0 & - & $\bullet$ & $\bullet$ & & $\bullet$ & $\bullet$ & ○ & ○ & ○ & ○ & 0 & $\bullet$ & & & 0 & $\bullet$ & & 0 & ○ & $\bullet$ & $\bullet$ & ○ \\
\hline & Mirf & - & - & $\bullet$ & ० & & $\bullet$ & • & • & C & ○ & ○ & - & $\bullet$ & $\bullet$ & & 0 & & & $\bullet$ & ○ & 0 & & ○ \\
\hline & Jain & & $\circ$ & $\bullet$ & ○ & & $\bullet$ & • & 0 & $\bullet$ & $\bullet$ & - & - & & $\bullet$ & ○ & & $\bullet$ & & 0 & ○ & $\bullet$ & $\bullet$ & 1 \\
\hline \multirow[t]{2}{*}{ Curcuminoids } & $\mathrm{Na}$ et al. [18] & - 0 & $\circ$ & $\bullet$ & 0 & & - & 0 & 0 & $\bullet$ & $\circ$ & - & 0 & & $\bullet$ & $\circ$ & $\theta$ & & & $\bullet$ & $\circ$ & $\bullet$ & $\bullet$ & 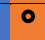 \\
\hline & Panah & $\bullet$ & - & 0 & - & $\bullet$ & $\bullet$ & $\bullet$ & 0 & ० & - & 0 & 0 & $\bullet$ & 0 & 0 & 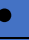 & $\bullet$ & & 0 & $\bullet$ & $\bullet$ & $\bullet$ & 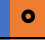 \\
\hline \multirow[t]{2}{*}{ Ginger } & Mozaffari-Khosravi et & $\bullet$ & - & $\bullet$ & $\bullet$ & $\bullet$ & 0 & $\bullet$ & 0 & ० & 0 & O & O & $\bullet$ & $\bullet$ & 0 & & & & 0 & & $\bullet$ & & 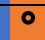 \\
\hline & Attar & $\bullet$ & - & & - & $\bullet$ & - & - & $\bullet$ & • & ○ & 0 & ० & $\bullet$ & $\bullet$ & ○ & $\bullet$ & $\bullet$ & & 0 & ○ & - & $\bullet$ & 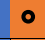 \\
\hline \multirow{2}{*}{ Propolis } & EI-Sharkawy et al. [43] & - & - & - & - & - & - & 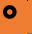 & - & - & - & - & - & - & - & - & - & - & & 0 & $\circ$ & - & - & 1 \\
\hline & Samadi et al. [44] & $\circ 0$ & $\circ$ & $\bullet$ & $\bullet$ & $\bullet$ & $\bullet$ & $\bullet$ & $\bullet$ & $\bullet$ & $\bullet$ & $\bullet$ & $\bullet$ & $\bullet$ & $\bullet$ & O & $\bullet$ & $\bullet$ & & 0 & ○ & $\bullet$ & & \\
\hline \multirow[t]{2}{*}{ Silybum marianum (L.) } & Garga & $\bullet$ & $\bullet$ & $\bullet$ & $\bullet$ & $\bullet$ & $\bullet$ & $\bullet$ & $\circ$ & $\bullet$ & $\circ$ & - & 0 & $\bullet$ & $\bullet$ & $\circ$ & & $\bullet$ & 0 & 0 & $\circ$ & $\bullet$ & $\bullet$ & 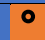 \\
\hline & Ebrahimpour-kouja & - & - & & $\bullet$ & - & - & - & - & - & - & - & - & - & $\circ$ & - & ○ & & & 0 & - & $\bullet$ & & \\
\hline Aloe vera & Zarrintan et al. [47] & 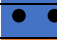 & - & $\bullet$ & $\bullet$ & $\bullet$ & $\bullet$ & 0 & O & 0 & $\bullet$ & $\circ$ & $\circ$ & $\circ$ & $\bullet$ & 0 & 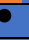 & - & $\circ \bullet$ & $\bullet$ & 0 & 0 & $\bullet$ & 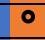 \\
\hline Andrographis paniculate & Widjajakusuma et al. [48] & $\circ 0$ & ० & $\bullet$ & 0 & $\bullet$ & $\bullet$ & 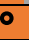 & ० & ० & O & 0 & ○ & 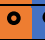 & $\bullet$ & 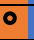 & $\bullet$ & $\bullet$ & 00 & 0 & $\bullet$ & $\bullet$ & $\bullet$ & 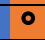 \\
\hline Cornus mas $\mathrm{L}$. & Soltani et al. [49] & $\circ \circ$ & $\circ$ & $\bullet$ & $\bullet$ & ○ & $\bullet$ & ० & O & - & $\bullet$ & 0 & ० & ० & $\bullet$ & ० & $\bullet$ & $\bullet$ & - 0 & 0 & ○ & $\bullet$ & $\bullet$ & 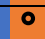 \\
\hline Daidzein & Ye e & 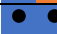 & - & - & 0 & $\bullet$ & - & 0 & 0 & - & - & - & $\circ$ & - & - & 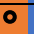 & - & - & 00 & $\bullet$ & 0 & - & $\bullet$ & $\circ$ \\
\hline Flaxseed & Javidi et al. [51] & $\bullet$ & - & $\bullet$ & 0 & $\bullet$ & $\bullet$ & ० & $\bullet$ & $\bullet$ & $\circ$ & $\bullet$ & - & $\bullet$ & $\bullet$ & 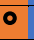 & $\bullet$ & • & - 0 & 0 & $\circ$ & $\bullet$ & $\bullet$ & $\bullet$ \\
\hline Garlic & Atkin et al. [52] & - 0 & $\circ$ & ० & $\bullet$ & $\circ$ & $\bullet$ & $\bullet$ & $\circ$ & ० & O & ० & ० & 0 & O & O & $\bullet$ & 0 & 00 & $\bullet$ & $\circ$ & $\bullet$ & $\bullet$ & $\bullet$ \\
\hline Glycyrrhiza Glabra L. & Alizadeh et al. [53 & 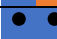 & $\bullet$ & $\bullet$ & 0 & $\bullet$ & 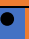 & 0 & $\bullet$ & $\bullet$ & $\bullet$ & 0 & 0 & $\bullet$ & $\bullet$ & 0 & $\bullet$ & $\bullet$ & 00 & $\bullet$ & 0 & 0 & $\bullet$ & 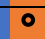 \\
\hline Ginkgo biloba extract & Aziz et al. [54] & $\circ \circ$ & 0 & $\bullet$ & 0 & $\bullet$ & 0 & 0 & 0 & 0 & 0 & o & 0 & 0 & $\bullet$ & 0 & $\bullet$ & $\bullet$ & 00 & 0 & 0 & $\bullet$ & $\bullet$ & $\bullet$ \\
\hline Morus alba & Trimarco et al. [55] & $\bullet$ & $\bullet$ & $\bullet$ & 0 & 0 & $\bullet$ & 0 & 0 & 0 & 0 & 0 & 0 & $\circ$ & O & 0 & $\bullet$ & O & 00 & 0 & $\bullet$ & $\bullet$ & $\bullet$ & 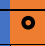 \\
\hline Nigella sative oil & Heshmati et al. [56] & $\bullet$ & - & $\bullet$ & $\bullet$ & $\bullet$ & $\bullet$ & 0 & - & • & $\bullet$ & 0 & 0 & $\bullet$ & $\bullet$ & 0 & $\bullet$ & 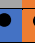 & 00 & $\bullet$ & - & $\bullet$ & $\bullet$ & - \\
\hline Psyllium & Abutair et al. [57] & $\circ \circ$ & $\circ$ & $\bullet$ & 0 & $\circ$ & $\bullet$ & 0 & 0 & 0 & 0 & 0 & 0 & $\bullet$ & 0 & 0 & • & 0 & 00 & 0 & 0 & $\bullet$ & $\bullet$ & $\bullet$ \\
\hline Red ginseng & Oh et al. [58] & $\bullet$ & -1 & $\bullet$ & $\circ$ & $\bullet$ & $\bullet$ & $\bullet$ & $\circ$ & $\circ$ & $\bullet$ & & $\circ$ & $\bullet$ & & $\bullet$ & 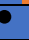 & & & 0 & & $\bullet$ & & 0 \\
\hline
\end{tabular}

full compliance; $\quad$ partial compliance; $\bigcirc$ non-compliance

this may partly be due to the current methodological shortcomings of RCT study designs and the complex characteristics of TCM, the results prompt further exploration about how to improve the methodology to build a stronger evidence-base that supports the use of TCM as nutraceuticals in diabetes management. There is also a clear need for training researchers in appropriate trial reporting as many of the gaps identified may have been closed if a more comprehensive report of their study was provided.

\section{Nutraceuticals as an adjunct therapy}

Integrating conventional and complementary medicines with integrated healthcare has been a global phenomenon in the past $2-3$ decades $[59,60]$. This trend is reflected by the constant demands for complementary medicines from patients. In 1998, a cancer centre in the United States established a multidisciplinary team to meet patients' needs for integrating conventional medicines and complementary medicines [61]. As of 2011, there was also a survey in Japan showed that almost $90 \%$ of doctors had forms of complementary medicines in their prescriptions [62]. A number of examples of using TCM as a complementary therapy to promote the self-management of diabetic patients are identified in the literature. In vitro studies suggested that cinnamon decreased the activity of intestinal maltase, sucrase, and pancreatic alpha-amylase and that this effect was additive with acarbose [63]. Some clinical research evaluated the effects of garlic when used in combination with antidiabetic drugs and showed that taking a specific garlic powder product $300 \mathrm{mg}$ three times daily in combination with metformin for 24 weeks could reduce fasting blood glucose approximately $70 \%$ more than with metformin alone in patients with type 2 diabetes [64]. Some TCM ingredients in this review have been shown to reduce levels of glucose and HbA1c or elevate plasma insulin levels through evidence from human or animal models, including curcuminoids, ginger, Aloe vera [6567]. Other ingredients were used traditionally as antidiabetic agents, such as Cornus mas L., daidzein genistein, Nigella sative oil [68-71]. These provide evidence that some diabetic patients have taken nutraceuticals containing TCM as a complementary treatment programme for a long time, however, there is still not enough evidence to put forward practical clinical recommendations. Combined with this assessment of the quality of RCT reports, the overall quality of current clinical trials 
Table 3 Risk of bias summary for studies included in this systematic review

\begin{tabular}{|c|c|c|c|c|c|c|c|c|c|}
\hline First author & $\begin{array}{l}\text { Sequence } \\
\text { generation } \\
\text { (selection } \\
\text { bias) }\end{array}$ & $\begin{array}{l}\text { Allocation } \\
\text { concealment } \\
\text { (selection } \\
\text { bias) }\end{array}$ & $\begin{array}{l}\text { Blinding } \\
\text { of participants } \\
\text { and personnel } \\
\text { (performance } \\
\text { bias) }\end{array}$ & $\begin{array}{l}\text { Blinding } \\
\text { of outcome } \\
\text { assessors } \\
\text { (detection } \\
\text { bias) }\end{array}$ & $\begin{array}{l}\text { Completeness } \\
\text { of outcome } \\
\text { data (attrition } \\
\text { bias) }\end{array}$ & $\begin{array}{l}\text { Selective } \\
\text { reporting } \\
\text { (reporting } \\
\text { bias) }\end{array}$ & $\begin{array}{l}\text { Academic } \\
\text { bias }\end{array}$ & $\begin{array}{l}\text { Sponsor } \\
\text { bias }\end{array}$ & Overall \\
\hline $\begin{array}{l}\text { Akilen et al. } \\
\text { [37] }\end{array}$ & Low & Unclear & Low & Low & Low & Unclear & High & High & High \\
\hline $\begin{array}{l}\text { Sharma et al. } \\
\text { [38] }\end{array}$ & Unclear & Low & Low & Low & High & High & Low & Unclear & High \\
\hline $\begin{array}{l}\text { Mirfeizi et al. } \\
\text { [39] }\end{array}$ & Unclear & Unclear & High & High & Low & Unclear & Low & High & High \\
\hline $\begin{array}{l}\text { Jain et al. } \\
\text { [40] }\end{array}$ & Low & Low & Low & Low & Low & Unclear & Low & Low & Unclear \\
\hline Na et al. [18] & High & Low & Low & Low & Low & Unclear & Low & Low & High \\
\hline $\begin{array}{l}\text { Panahi et al. } \\
\text { [41] }\end{array}$ & Unclear & Unclear & Unclear & Unclear & Unclear & Unclear & High & High & High \\
\hline $\begin{array}{l}\text { Mozaffari- } \\
\text { Khosravi } \\
\text { et al. [19] }\end{array}$ & Low & Unclear & Low & Unclear & Low & Low & Low & High & High \\
\hline $\begin{array}{l}\text { Attari et al. } \\
\text { [42] }\end{array}$ & Low & Low & Unclear & Unclear & Low & Unclear & High & High & High \\
\hline $\begin{array}{l}\text { El-Sharkawy } \\
\text { et al. [43] }\end{array}$ & Low & Low & Low & Unclear & Low & Unclear & Low & High & High \\
\hline $\begin{array}{l}\text { Samadi et al. } \\
\text { [44] }\end{array}$ & Low & Unclear & Unclear & Unclear & Low & Unclear & Low & High & High \\
\hline $\begin{array}{l}\text { Gargari et al. } \\
{[45]}\end{array}$ & Low & High & Low & Low & Low & Low & High & High & High \\
\hline $\begin{array}{l}\text { Ebrahim- } \\
\text { pour-kou- } \\
\text { jan et al. } \\
{[46]}\end{array}$ & Low & High & Low & Low & Low & Low & High & High & High \\
\hline $\begin{array}{l}\text { Zarrintan } \\
\text { et al. [47] }\end{array}$ & Low & Unclear & Low & Low & Low & Unclear & High & High & High \\
\hline $\begin{array}{l}\text { Widjajaku- } \\
\text { suma et al. } \\
\text { [48] }\end{array}$ & Unclear & Unclear & Unclear & Unclear & Unclear & Unclear & Low & Low & Unclear \\
\hline $\begin{array}{l}\text { Soltani et al. } \\
\text { [49] }\end{array}$ & Unclear & Unclear & Low & Low & Low & Unclear & High & High & High \\
\hline Ye et al. [50] & Low & Low & Low & Low & Unclear & Low & Low & Low & Unclear \\
\hline $\begin{array}{l}\text { Javidi et al. } \\
\text { [51] }\end{array}$ & Unclear & Unclear & Unclear & Unclear & Low & Low & Low & Low & Unclear \\
\hline $\begin{array}{l}\text { Atkin et al. } \\
{[52]}\end{array}$ & Unclear & Unclear & High & High & Low & Unclear & Low & Low & High \\
\hline $\begin{array}{l}\text { Alizadeh } \\
\text { et al. [53] }\end{array}$ & Low & Low & Low & High & Low & Unclear & Low & High & High \\
\hline $\begin{array}{l}\text { Aziz et al. } \\
\text { [54] }\end{array}$ & Unclear & Unclear & Unclear & Unclear & Unclear & Low & High & High & High \\
\hline $\begin{array}{l}\text { Trimarco } \\
\text { et al. [55] }\end{array}$ & Unclear & Unclear & Unclear & Unclear & Unclear & Unclear & Low & Unclear & Unclear \\
\hline $\begin{array}{l}\text { Heshmati } \\
\text { et al. [56] }\end{array}$ & Low & Low & Low & Low & Low & low & Low & High & High \\
\hline $\begin{array}{l}\text { Abutair et al. } \\
\text { [57] }\end{array}$ & Low & Unclear & Unclear & Unclear & Low & Unclear & Low & Low & Unclear \\
\hline Oh et al. [58] & Low & Unclear & Unclear & Unclear & Low & Low & High & High & High \\
\hline
\end{tabular}

Low_low risk of bias; Unclear_unclear risk of bias; High—high risk of bias 
does not sufficiently ensure the long-term safety and effectiveness of nutraceuticals containing TCM as complementary therapies.

\section{Major areas of improvement in the RCT design}

Taking the evaluation results into account, there are some limitations in the studies included in this review. Firstly, the overall quality of the studies was poor. Whether through the CONSORT checklist statement or the Cochrane risk-of-bias tool, explanations for generating randomisation and blinding are necessary to avoid RCTs bias. However, only half of the studies reported randomisation methods generated via random sequences and only six studies (25\%) reported the detailed blinding procedures, which may lead to perceptions of performance bias and detection bias [72]. Therefore, it is necessary to fully report the specific details of randomization and blinding measures in accordance with the CONSORT checklist in the RCTs. Meanwhile, the Chinese Concort Group for TCM has submitted precise reports of TCM interventions and outcome measures in order to improve the quality of TCM research [73]. An RCT guideline that is specific for nutraceuticals combined the CONSORT 2010 checklist with the reports of TCM may be a better choice for the future research.

Secondly, most sample sizes in the included studies were small. Seven studies (29.2\%) had a small sample size of less than 50,11 studies $(45.8 \%)$ had a sample size between 50 and 100, and the others (25\%) ranged in sample size between 100 and 200. This situation often leads to a lack of statistical ability to properly estimate the effect of treatment, while also overestimating the risk of intervention benefit. Most of the subjects in this review required patients with diabetes when recruiting in the hospital, while diabetic patients needed long-term medication or insulin treatment. It was difficult to determine whether or not patients maintained the original drug regimen, or added the nutraceutical supplement, or executed intervention after entering the washout period.

Thirdly, all periods of the reported studies ranged from 4 to 24 weeks, and the periods of 10 studies were less than or equal to 8 weeks. While the short-term design was sufficient to demonstrate some immediate effects of the nutraceuticals on reducing blood glucose level, the long-term effects on the overall management of diabetes were not fully investigated. For example, the duration of the RCTs is important to detect reliable HbA1c changes. HbA1c can reflect a long-term average blood glucose level, and the change mostly depends on red blood cells' life span, which varies from person to person. In addition, it has been proven that it usually takes 1 month for HbA1c changes to reach its $50 \%$ maximum capacity, and 2 months for $80 \%$ changes [74]. Therefore, performing a trial of at least 2 months would cover the subject's difference in red blood cell life span. In addition, the sustainable efficacy issues of long-term use of nutraceuticals containing TCM are also worthy of further consideration.

Although many of the issues surrounding the safety and effectiveness of nutraceuticals and TCM used in modern society have not been effectively addressed, improving the quality of RCT reports can provide a larger evidence base. Therefore, the design of future RCTs should pay more attention to randomisation and blinding measures, increase sample size and duration of trials, completed reporting and analysis of adverse reactions.

\section{Other safety concerns regarding the use of nutraceuticals in managing diabetes}

Many users believe that it is not necessary to consult their healthcare provider before taking nutraceuticals especially when these products were not sold as drug in the market or defined as medicines by the authority such as the US Food and Drug Administration [75]. However, with at least 23,000 emergency medical visits per year being related to nutraceuticals or dietary supplements in the US between 2004 and 2013, nutraceuticals are certainly not as safe as many assume [76]. At present, the most common safety issues for nutraceuticals containing TCM are the interactions of the bioactive components themselves in TCM (TCM-TCM), and the interactions between nutraceuticals containing TCM and conventional medicines.

\section{TCM-TCM interactions}

Traditional medicine practitioners and medical professionals generally believe that ingredient herbal formulations are usually effective because of their long history of successful use [77]. However, the interaction of the TCM ingredients may result in a change in the efficacy of the formulations, and may even enhance or ameliorate adverse effects [77]. Many of the latest publications are now studying the interaction of TCM ingredients. On the one side, Shoba et al. [78] has long shown in theirs' research that piperine can enhance the serum concentration, absorption and bioavailability of curcumin both in rats and humans without side effects. Studies by Hassan et al. [79] showed that cinnamon-ginger mixture extract improved the glucose levels, serum triglycerides and other biochemical indicators in gestational diabetic rats. On the other side, the methanolic extract of Panax ginseng added to aristolochic acid-treated proximal tubule epithelial cells (HK-2 cells) was found to induce renal epithelial cells to accelerate apoptosis [80]. Considering the possibility of interactions, positive or negative, among the TCM ingredients, the overall safety deserve more attention even if each individual nutraceutical has been shown to be effective. 


\section{TCM-conventional medicine interactions}

The increased global use of nutraceutical containing TCM, and a lack of accurate information about nutraceutical containing TCM being available to healthcare providers and patients, have increased concerns about the interactions of TCM and conventional medicines [81]. A recent review of studies on herb-drug interaction published between 2000 and 2014 showed that the number of such reports continued to increase and most studies examined the pharmacokinetic interactions through in vivo studies, in vitro studies, and review studies [82]. More studies, especially clinical studies focusing on pharmacodynamics, are warranted to fully investigate the safety profile of nutraceuticals containing TCM. Only $7.4 \%$ of the publications analysed the interaction of TCM with the treatment of diabetes drugs, and most current research focuses on tumour and circulatory diseases [82]. Studies have shown that there is a positive or negative interaction between TCM and conventional medicines to increase or decrease the efficacy of traditional drugs [83]. Ashraf et al. [84] have confirmed that the combination of appropriate garlic extract (Allium sativum L.) and metformin showed a significant reduction in fasting blood glucose compared to using alone metformin $(P<0.05)$, and their study also reported that the interaction caused a significant decrease in the mean total cholesterol level $(P<0.05)$. In contrast, a case study reported in 2015 showed that the combination of cinnamon and statins has the potential for significant liver damage and it should be discouraged [85], what's more, in the theoretical point of view, concurrent use of cinnamon with blood sugar-lowering agents may have additive effects and increase the risk of hypoglycemia [86].

\section{Potential adverse reactions}

Studies have shown that in RCTs, adverse reactions of TCM for treatment are rarely observed compared with placebo groups [87]. However, RCTs cannot reliably detect rare adverse events or have a significant incidence of latency time [88]. Di Lorenzo et al. [89] pointed out in a systematic review that $32 \%$ of the adverse reactions of plant-based nutraceuticals and preparations were caused by soybean (Glycine max) and licorice (Glycyrrhiza glabra), and the two are included in this evaluation. Seven of twenty-four studies reported adverse reactions, and three were gastrointestinal reactions in this evaluation, but none of them reported the cause of the adverse reactions. Especially for chronic diseases, adverse reactions are caused not only by conventional causes such as pharmacokinetics, but also by exposure to other compounds (alcohol, nicotine) and heterogeneity factors in nutraceuticals that confuse them with mechanism of clinical adverse reactions during the long-term administration. Therefore, future RCT models for nutraceuticals should take into account the need to assess the risks of drug-herb interactions and the adverse reactions associated with long-term use.

Overall, paying attention to the quality of RCT reports is critical to improving the evidence-base for nutraceuticals containing TCM for diabetes management. In addition, clinical data about the long-term safety (including case reports, post-marketing surveillance studies, etc.) is also important for developing a more complete safety profile as nutraceuticals compsing of TCM may be used continuously in diabetes management.

\section{Limitation}

This systematic review based on the existing standards for literature retrieval, evaluation and data synthesis, presents a complete view of the nutraceuticals containing TCM for diabetes management and the quality of its RCT reports. Nevertheless, our study has some limitations. Firstly, 16 of the 24 studies were conducted strictly for diabetic patients, with each of them employing different study design. To further develop the evidence base about nutraceuticals containing TCM in diabetic management, more rigorously designed clinical trials are needed. Secondly, the publication bias cannot be completely ruled out, that is, regardless of the methodological quality, the data showed according to the results are unlikely to fully present the negative findings. What's more, we only reviewed the TCM herbs listed in the Chinese Pharmacopoeia, but the TCM mentioned in this study is also included in the pharmacopoeia of other countries, and can expand the scope of TCM in future research to analyze more RCT reports. Another limitation in this study was the exclusion of Chinese publications. In the preliminary literature search, a literature search at the National Knowledge Infrastructure CNKI using the same search strategy was conducted but we were not able to identify any Chinese publications which investigated the evidence base for the efficacy about TCM used as nutraceuticals for diabetic management. To further illustrate the evidence base about the efficacy of TCM which can potentially be used as a nutraceutical, another larger-scale systematic literature review is underway which aims to identify TCM shown to be effective in diabetic management and can be defined as nutraceuticals according to the regulations in different countries. 


\section{Conclusion}

There is some evidence obtained from clinical trials to support a role for nutraceuticals containing TCM in the management of diabetes. However these findings are tempered by the overall poor quality of trial reporting and therefore caution is required in translating these findings to clinical practice and standard care. More rigorous long-term clinical trials to investigate both safety and efficacy of TCM nutraceuticals are warranted and authors are encouraged to follow detailed guidelines for reporting RCTs.

\begin{abstract}
Abbreviations
TCM: traditional Chinese medicine; RCTs: randomized controlled trials; FBG: fasting blood glucose; PBG: postprandial 2-h blood glucose; HbA1 c: glycated hemoglobin; T1DM: type 1 diabetes mellitus; T2DM: type 2 diabetes mellitus; ADA: American Diabetes Association; IGT: impaired glucose tolerance; IFG: impaired fasting glucose; MetS: metabolic syndrome (MetS).
\end{abstract}

\section{Acknowledgements}

Not applicable.

\section{Author contributions}

SJ and UCOL planned and designed the study. JS, COLU, HH, WYT were responsible for data management and analysis. ZL, XZ and HH contributed to interpretation of study results. JS and COLU drafted the manuscript. JH and $\mathrm{HH}$ critically reviewed and revised the manuscript. All authors read and approved the final manuscript.

\section{Funding}

This research was funded by Macau Science and Technology Development Fund (Grant No. 071/2017/A2) and National Key Research and Development Program of China (Grant No. 2017YFE0191500).

\section{Availability of data and materials}

All data are fully available without restriction.

\section{Consent for publication}

Not applicable.

\section{Competing interests}

The authors declare that they have no competing interests.

\section{Author details}

${ }^{1}$ State Key Laboratory of Quality Research in Chinese Medicine, Institute of Chinese Medical Sciences, University of Macau, Taipa, Macao. ${ }^{2}$ The University of Sydney School of Pharmacy, Faculty of Medicine and Health, The University of Sydney, New South Wales, Australia.

Received: 30 August 2019 Accepted: 7 November 2019

Published online: 29 November 2019

\section{References}

1. Shaw JE, Sicree RA, Zimmet PZ. Global estimates of the prevalence of diabetes for 2010 and 2030. Diabetes Res Clin Pract. 2010;87(1):4-14.

2. Santaguida $\mathrm{PL}$, et al. Diagnosis, prognosis, and treatment of impaired glucose tolerance and impaired fasting glucose. Evid Rep Technol Assess (Summ). 2005;128:1

3. Montonen J, Knekt $\mathrm{P}$, Järvinen $\mathrm{R}$, et al. Dietary antioxidant intake and risk of type 2 diabetes. Diabetes Care. 2004;27(2):362-6.

4. Tahrani AA, Piya MK, Kennedy A, et al. Glycaemic control in type 2 diabetes: targets and new therapies. Pharmacol Ther. 2010;125(2):328-61.

5. Yeh GY, Eisenberg DM, KaptchukTJ, Phillips RS. Systematic review of herbs and dietary supplements for glycemic control in diabetes. Diabetes Care. 2003;26(4):1277-94.
6. Birdee GS, Yeh G. Complementary and alternative medicine therapies for diabetes: a clinical review. Clin Diabetes. 2010;28(4):147-55.

7. Pandey KB, Rizvi SI. Plant polyphenols as dietary antioxidants in human health and disease. Oxid Med Cell Longev. 2009;2(5):270-8.

8. Bahadoran Z, Golzarand M, Mirmiran P, et al. Dietary total antioxidant capacity and the occurrence of metabolic syndrome and its components after a 3-year follow up in adults: tehran lipid and glucose study. Nutrition \& Metabolism. 2012;9(1):70.

9. Lin AX, Chan G, Hu Y, et al. Internationalization of traditional Chinese medicine: current international market, internationalization challenges and prospective suggestions. Chin Med. 2018;13(1):9.

10. Ma HD, Deng YR, Tian Z, et al. Traditional Chinese medicine and immune regulation. Clin Rev Allergy Immunol. 2013;44(3):229-41.

11. Bent S. Herbal medicine in the United States: review of efficacy, safety, and regulation. J Gen Intern Med. 2008;23(6):854-9.

12. Li J, Zhu J, Hu H, et al. Internationalization of Traditional/Complementary Medicine products: market entry as medicine. Chin Med. 2018;13(1):50.

13. Chang CLT, Lin Y, Bartolome AP, et al. Herbal therapies for type 2 diabetes mellitus: chemistry, biology, and potential application of selected plants and compounds. Evid Based Complement Altern Med. 2013;2013:26.

14. Das $L$, Bhaumik E, Raychaudhuri $U$, et al. Role of nutraceuticals in human health. J Food Sci Technol. 2012:49(2):173-83.

15. Nasri $H$, Baradaran $A$, Shirzad $H$, et al. New concepts in nutraceuticals as alternative for pharmaceuticals. Int J Prev Med. 2014;5(12):1487.

16. Wang JJ, Xu FX, Feng XQ, et al. Research on health food of Chinese herbal medicine: appraisal and suggestions from viewpoint of food science. J Food Saf Qual. 2015;6(4):1350-5.

17. Calixto JB. Efficacy, safety, quality control, marketing and regulatory guidelines for herbal medicines (phytotherapeutic agents). Braz J Med Biol Res. 2000;33(2):179-89.

18. Na LX, Li Y, Pan HZ, et al. Curcuminoids exert glucose-lowering effect in type 2 diabetes by decreasing serum free fatty acids: a double-blind, placebo-controlled trial. Mol Nutr Food Res. 2013;57(9):1569-77.

19. Mozaffari-Khosravi $H$, Talaei $B$, Jalali BA, et al. The effect of ginger powder supplementation on insulin resistance and glycemic indices in patients with type 2 diabetes: a randomized, double-blind, placebo-controlled trial. Complement Ther Med. 2014;22(1):9-16.

20. Chinese Pharmacopoeia Commission. Pharmacopoeia of the People's Republic of China. 1 (2010). China Medical Science Press. 2010.

21. American Diabetes Association. Diagnosis and classification of diabetes mellitus. Diabetes Care. 2010;33(supplement 1):S62-9.

22. Grundy SM. Pre-diabetes, metabolic syndrome, and cardiovascular risk. J Am Coll Cardiol. 2012;59(7):635-43.

23. World Health Organization. WHO Expert Committee on diabetes Mellitus: second report. WHO Technical Report Series. Geneva: World Health Organization; 2011. p. 646.

24. Chan JCN, et al. Diabetes in Asia: epidemiology, risk factors, and pathophysiology. JAMA. 2009;301(20):2129-40.

25. Balkau B, Vernay M, Mhamdi L, et al. The incidence and persistence of the NCEP (National Cholesterol Education Program) metabolic syndrome. The French DESIR study. Diabetes Metabol. 2003:29(5):526-32.

26. National Diabetes Data Group. Classification and diagnosis of diabetes mellitus and other categories of glucose intolerance. Diabetes. 1979;28(12):1039-57.

27. Jia W. Standardising HbA1c-based diabetes diagnosis: opportunities and challenges. Expert Rev Mol Diagn. 2016;16(3):343-55.

28. World Health Organization. Use of glycated haemoglobin (HbA1c) in diagnosis of diabetes mellitus: abbreviated report of a WHO consultation. Geneva: World Health Organization; 2011.

29. Jeffcoate SL. Diabetes control and complications: the role of glycated haemoglobin, 25 years on. Diabet Med. 2004;21(7):657-65.

30. Muniyappa R, Lee $\mathrm{S}$, Chen $\mathrm{H}$, et al. Current approaches for assessing insulin sensitivity and resistance in vivo: advantages, limitations, and appropriate usage. Am J Physiol Endocrinol Metabol. 2008;294(1):E15-26.

31. Shoaei T, Heidari-Beni M, Tehrani HG. Effects of probiotic supplementation on pancreatic $\beta$-cell function and c-reactive protein in women with polycystic ovary syndrome: a randomized double-blind placebocontrolled clinical trial. Int J Prev Med. 2015;6:27.

32. Schulz KF, Altman DG, Moher D. CONSORT 2010 statement: updated guidelines for reporting parallel group randomised trials. BMC Med. 2010;8(1):18. 
33. Higgins JPT, Altman DG, Gøtzsche PC, et al. The Cochrane Collaboration's tool for assessing risk of bias in randomised trials. BMJ. 2011;343:d5928.

34. Whitehead M. The concepts and principles of equity and health. Health Promotion Int. 1991;6(3):217-28.

35. King DL, Delfabbro PH, Griffiths MD, et al. Assessing clinical trials of Internet addiction treatment: a systematic review and CONSORT evaluation. Clin Psychol Rev. 2011;31(7):1110-6.

36. Turner $L$, Shamseer $L$, Altman DG, et al. Does use of the CONSORT Statement impact the completeness of reporting of randomised controlled trials published in medical journals? A Cochrane review a. Syst Rev. 2012:1(1):60.

37. Akilen R, Tsiami A, Devendra D, et al. Glycated haemoglobin and blood pressure-lowering effect of cinnamon in multi-ethnic Type 2 diabetic patients in the UK: a randomized, placebo-controlled, double-blind clinical trial. Diabet Med. 2010;27(10):1159-67.

38. Sharma P, Sharma S, Agrawal RP, et al. A randomised double blind placebo control trial of cinnamon supplementation on glycemic control and lipid profile in type 2 diabetes mellitus. Aust J Herbal Med. 2012;24(1):4.

39. Mirfeizi M, Mehdizadeh Tourzani Z, Mirfeizi SZ, et al. Controlling type 2 diabetes mellitus with herbal medicines: a triple-blind randomized clinical trial of efficacy and safety. J Diabetes. 2016;8(5):647-56.

40. Jain SG, Puri S, Misra A, et al. Effect of oral cinnamon intervention on metabolic profile and body composition of Asian Indians with metabolic syndrome: a randomized double-blind control trial. Lipids Health Dis. 2017;16(1):113.

41. Panahi $Y$, Hosseini MS, Khalili N, et al. Antioxidant and anti-inflammatory effects of curcuminoid-piperine combination in subjects with metabolic syndrome: a randomized controlled trial and an updated meta-analysis. Clin Nutr. 2015;34(6):1101-8.

42. Attari VE, Mahluji S, Jafarabadi MA, et al. Effects of supplementation with ginger (Zingiber officinale Roscoe) on Serum glucose, lipid profile and oxidative stress in obese women: a randomized, placebo-controlled clinical trial. J Pharm Sci. 2015;21(4):184-91.

43. El-Sharkawy HM, Anees MM, Van Dyke TE. Propolis improves periodontal status and glycemic control in patients with type 2 diabetes mellitus and chronic periodontitis: a randomized clinical trial. J Periodontol. 2016;87(12):1418-26.

44. Samadi N, Mozaffari-Khosravi $H$, Rahmanian M, et al. Effects of bee propolis supplementation on glycemic control, lipid profile and insulin resistance indices in patients with type 2 diabetes: a randomized, doubleblind clinical trial. J Integr Med. 2017;15(2):124-34.

45. Gargari BP, Mobasseri M, Valizadeh $\mathrm{H}$, et al. Effects of Silybum marianum (L.) Gaertn.(silymarin) extract supplementation on antioxidant status and hs-CRP in patients with type 2 diabetes mellitus: a randomized, tripleblind, placebo-controlled clinical trial. Phytomedicine. 2015;22(2):290-6.

46. Ebrahimpour-koujan S, Gargari BP, Mobasseri M, et al. Lower glycemic indices and lipid profile among type 2 diabetes mellitus patients who received novel dose of Silybum marianum (L.) Gaertn.(silymarin) extract supplement: a triple-blinded randomized controlled clinical trial. Phytomedicine. 2018;44:39-44.

47. Zarrintan A, Mobasseri M, Zarrintan A, et al. Effects of aloe vera supplements on blood glucose level and lipid profile markers in type 2 diabetic patients-a randomized clinical trial. Pharm Sci. 2015;21(2):65.

48. Widjajakusuma EC, Jonosewojo A, Hendriati L, et al. Phytochemical screening and preliminary clinical trials of the aqueous extract mixture of Andrographis paniculata (Burm. f.) Wall. ex Nees and Syzygium polyanthum (Wight.) Walp leaves in metformin treated patients with type 2 diabetes. Phytomedicine. 2019;55:137-47.

49. Soltani R, Gorji A, Asgary S, et al. Evaluation of the effects of Cornus mas L. fruit extract on glycemic control and insulin level in type 2 diabetic adult patients: a randomized double-blind placebo-controlled clinical trial. Evid Based Compl Altern Med. 2015;2015:49.

50. Ye YB, Chen AL, Lu W, et al. Daidzein and genistein fail to improve glycemic control and insulin sensitivity in Chinese women with impaired glucose regulation: a double-blind, randomized, placebo-controlled trial. Mol Nutr Food Res. 2015;59(2):240-9.

51. Javidi A, Mozaffari-Khosravi H, Nadjarzadeh A, et al. The effect of flaxseed powder on insulin resistance indices and blood pressure in prediabetic individuals: a randomized controlled clinical trial. J Res Med Sci. 2016;21:135-8.
52. Atkin $M$, Laight $D$, Cummings $M H$. The effects of garlic extract upon endothelial function, vascular inflammation, oxidative stress and insulin resistance in adults with type 2 diabetes at high cardiovascular risk. A pilot double blind randomized placebo controlled trial. J Diabetes Compl. 2016:30(4):723-7.

53. Alizadeh M, Namazi N, Mirtaheri E, et al. Changes of insulin resistance and adipokines following supplementation with Glycyrrhiza glabra L. extract in combination with a low-calorie diet in overweight and obese subjects: a randomized double blind clinical trial. Adv Pharm Bull. 2018:8(1):123.

54. Aziz TA, Hussain SA, Mahwi TO, et al. The efficacy and safety of Ginkgo biloba extract as an adjuvant in type 2 diabetes mellitus patients ineffectively managed with metformin: a double-blind, randomized, placebocontrolled trial. Drug Desig Dev Ther. 2018;12:735.

55. Trimarco V, Izzo R, Stabile E, et al. Effects of a new combination of nutraceuticals with Morus alba on lipid profile, insulin sensitivity and endotelial function in dyslipidemic subjects. A cross-over, randomized, double-blind trial. High Blood Press Cardiovasc Prev. 2015;22(2):149-54.

56. Heshmati J, Namazi N, Memarzadeh MR, et al. Nigella sativa oil affects glucose metabolism and lipid concentrations in patients with type 2 diabetes: a randomized, double-blind, placebo-controlled trial. Food Res Int. 2015;70:87-93.

57. Abutair AS, Naser IA, Hamed AT. Soluble fibers from psyllium improve glycemic response and body weight among diabetes type 2 patients (randomized control trial). Nutr J. 2016;15(1):86.

58. Oh MR, Park SH, Kim SY, et al. Postprandial glucose-lowering effects of fermented red ginseng in subjects with impaired fasting glucose or type 2 diabetes: a randomized, double-blind, placebo-controlled clinical trial. BMC Complement Altern Med. 2014;14(1):237.

59. Leach MJ, Eaton $\mathrm{H}$, Agnew T, et al. The effectiveness of integrative healthcare for chronic disease: a systematic review. Int J Clin Pract. 2019;73(4):e13321.

60. Treister-Goltzman Y, Peleg R. Trends in publications on complementary and alternative medicine in the medical literature. J Complement Integr Med. 2015;12(2):111-5.

61. Coss RA, McGrath P, Caggiano V. Alternative care patient choices for adjunct therapies within a cancer center. Cancer Pract. 1998;6(3):176-81.

62. Japan Kampo Medicines Manufacturers Association (JKMA). http://www. nikkankyo.org/index.html. Accessed 20 Oct 2016.

63. Natural Medicines. Saigon Cinnamon [Monograph]. Natural standard professional monograph. 2018. http://naturalmedicines-therapeuticrese arch-com.db15.linccweb.org/. Accessed 6 Sept 2018.

64. Natural Medicines. Garlic [Monograph]. Natural standard professional monograph. 2019a. http://naturalmedicines-therapeuticresearch-com. db15.linccweb.org/. Accessed 11 March 2019.

65. Natural Medicines. Turmeric [Monograph]. Natural standard professional monograph. 2019b. http://naturalmedicines-therapeuticresearch-com. db15.linccweb.org/. Accessed 1 Aug 2019.

66. Natural Medicines. Ginger [Monograph]. Natural standard professional monograph. 2019c. http://naturalmedicines-therapeuticresearch-com. db15.linccweb.org/. Accessed 12 July 2019.

67. Natural Medicines. Aloe [Monograph]. Natural standard professional monograph. 2019d. http://naturalmedicines-therapeuticresearch-com. db15.linccweb.org/. Accessed 18 Mar 2019.

68. Dinda B, Kyriakopoulos AM, Dinda S, et al. Cornus mas L.(cornelian cherry), an important European and Asian traditional food and medicine: Ethnomedicine, phytochemistry and pharmacology for its commercial utilization in drug industry. J Ethnopharmacol. 2016;193:670-90.

69. Chen Kl, Erh MH, Su NW, et al. Soyfoods and soybean products: from traditional use to modern applications. Appl Microbiol Biotechnol. 2012;96(1):9-22.

70. Ramadan MF. Nutritional value, functional properties and nutraceutical applications of black cumin (Nigella sativa L.): an overview. Int J Food Sci Technol. 2007;42(10):1208-18.

71. Liao $L, H e Y, L i L$, et al. A preliminary review of studies on adaptogens: comparison of their bioactivity in TCM with that of ginseng-like herbs used worldwide. Chin Med. 2018;13(1):57.

72. Lu L, Li H, Fu D, et al. Rhubarb root and rhizome-based Chinese herbal prescriptions for acute ischemic stroke: a systematic review and metaanalysis. Complement Ther Med. 2014;22(6):1060-70

73. Bian ZX, Moher D, Li YP, et al. Appropriately selecting and concisely reporting the outcome measures of randomized controlled trials of 
traditional Chinese medicine. Zhong Xi Yi Jie He Xue Bao J Chin Integr Med. 2008;6(8):771-5.

74. Hirst JA, Stevens RJ, Farmer AJ. Changes in HbA1c level over a 12-week follow-up in patients with type 2 diabetes following a medication change. PLoS ONE. 2014;9(3):e92458.

75. Wu CH, Wang CC, Kennedy J. Changes in herb and dietary supplement use in the US adult population: a comparison of the 2002 and 2007 National Health Interview Surveys. Clin Ther. 2001;33(11):1749-58.

76. Geller Al, Shehab N, Weidle NJ, et al. Emergency department visits for adverse events related to dietary supplements. N Engl J Med. 2015;373(16):1531-40.

77. Enioutina EY, Salis ER, Job KM, et al. Herbal Medicines: challenges in the modern world. Part 5 status and current directions of complementary and alternative herbal medicine worldwide. Expert Rev Clin Pharmacol. 2017;10(3):327-38.

78. Shoba G, Joy D, Joseph T, et al. Influence of piperine on the pharmacokinetics of curcumin in animals and human volunteers. Planta Med. 1998;64(04):353-6.

79. El-Ghawet HA, El-Sayyad HIH, Ghanem NFF, et al. Cinnamon and ginger combined extract improved diabetic induced developmental defects of inner ear and teeth of rat fetuses. J Preg Child Health. 2019;6(411):2.

80. Bunel V, Antoine MH, Nortier J, et al. In vitro effects of panax ginseng in aristolochic acid-mediated renal tubulotoxicity: apopto-sis versus regeneration. Planta Med. 2015:81:363-72.

81. Cramer H, Cohen L, Dobos G, et al. Integrative oncology: best of both worlds-theoretical, practical, and research issues. Evid Based Complement Altern Med. 2013;2013:6.

82. Choi JG, Eom SM, Kim J, et al. A comprehensive review of recent studies on herb-drug interaction: a focus on pharmacodynamic interaction. J Altern Complemen Med. 2016;22(4):262-79.
83. Cheng CW, Fan W, Ko SG, et al. Evidence-based management of herb-drug interaction in cancer chemotherapy. Explore J Sci Heal. 2010;6(5):324-9.

84. Ashraf R, Khan RA, Ashraf I. Garlic (Allium sativum) supplementation with standard antidiabetic agent provides better diabetic control in type 2 diabetes patients. Pak J Pharm Sci. 2011;24(4):565-70.

85. Brancheau D, Patel B, Zughaib M. Do cinnamon supplements cause acute hepatitis? Am J Case Rep. 2015;16:250-4.

86. Ulbricht C, Seamon E, Windsor RC, et al. An evidence-based systematic review of cinnamon (Cinnamomum spp.) by the natural standard research collaboration. J Diet Suppl. 2011;8(4):378-454.

87. Izzo AA, Hoon-Kim S, Radhakrishnan R, et al. A critical approach to evaluating clinical efficacy, adverse events and drug interactions of herbal remedies. Phytother Res. 2016;30(5):691-700.

88. Berlin JA, Glasser SC, Ellenberg SS. Adverse event detection in drug development: recommendations and obligations beyond phase 3. Am J Public Health. 2008;98(8):1366-71.

89. Di Lorenzo C, Ceschi A, Kupferschmidt $H$, et al. Adverse effects of plant food supplements and botanical preparations: a systematic review with critical evaluation of causality. Br J Clin Pharmacol. 2015;79(4):578-92.

\section{Publisher's Note}

Springer Nature remains neutral with regard to jurisdictional claims in published maps and institutional affiliations.
Ready to submit your research? Choose BMC and benefit from:

- fast, convenient online submission

- thorough peer review by experienced researchers in your field

- rapid publication on acceptance

- support for research data, including large and complex data types

- gold Open Access which fosters wider collaboration and increased citations

- maximum visibility for your research: over $100 \mathrm{M}$ website views per year

At BMC, research is always in progress.

Learn more biomedcentral.com/submissions 